[CONTRIBUtion FROM THE CHEMICAL LABORATORY OF LEHIGH UNIVERSITY.]

\title{
THE SOLUBILITY OF SODIUM METAVANADATE.
}

By D. J. MCADAM, JR., AND C. A. PIERLE.

Received March 21, 1912.

In making some experiments on the atomic weight of vanadium, ${ }^{1}$ it was necessary for one of us to recrystallize sodium metavanadate quite often. In this work it was noticed that the crystals seemed to vary considerably in solubility and appearance.

Since we were not able to find anything definit on this subject in the literature of vanadium, it seemed worth while to investigate the solubility of sodium metavanadate, and to determin what hydrates occur in contact with the water solution.

Historical.-A. Ditte says that $\mathrm{NaVO}_{3} 2 \mathrm{H}_{2} \mathrm{O}$ is obtained by allowing solutions to evaporate over sulfuric acid. He also says that he obtained crystals with $2^{1} / 2,3$ and $4 \mathrm{H}_{2} \mathrm{O}$ by addition of alcohol to water solutions of sodium vanadate. Nothing was given about the solubility of these salts except the statement that they are slowly soluble in cold water and easily soluble in hot water.

In this laboratory in 1909, H. E. Maddock, at the suggestion of one of us, made a number of determinations of the solubility of sodium metavanadate. Most of the determinations were made at $25^{\circ}$, and the results varied from about $\mathrm{I}_{4}{ }^{1} / 2$ to $2 \mathrm{O}^{1} / 2$ grams of vanadate to 100 grams of water. $\mathrm{He}$ also made one determination each at temperatures of $45^{\circ}, 60^{\circ}$ and $75^{\circ}$, getting values of $24.7,33.6$ and 40.8 grams respectively. The last two results agree very well with those of curve $A$ as shown below. The explanation of the varying results at $25^{\circ}$ is given later.

Preparation of Material.--Several samples of sodium metavanadate were prepared, but the method was in all cases practically the same, so only one preparation will be described.

Iron vanadate, the kind used in the preparation of ferrovanadium, was boiled with a strong solution of sodium carbonate or sodium hydroxide, filtered, and extracted several times with hot water containing sodium carbonate. The filtrate contained sodium vanadate, with the excess of alkali and some iron. It was acidified with sulfuric acid, which precipitated vanadic acid, leaving the iron and most of the sodium sulfate in solution; it was filtered with suction and washed repeatedly, but it was found impossible to wash out all the sulfate. As a means of removing this sulfate and also possible traces of phosphoric acid, the vanadic acid was then reduced to vanadyl oxalate by heating with oxalie acid. The equation is: $\mathrm{V}_{2} \mathrm{O}_{5}+{ }_{3} \mathrm{H}_{2} \mathrm{C}_{2} \mathrm{O}_{4}=2 \mathrm{VO}\left(\mathrm{C}_{2} \mathrm{O}_{4}\right)+{ }_{3} \mathrm{H}_{2} \mathrm{O}+{ }_{2} \mathrm{CO}_{2}$. Enough ammonium oxalate was now added to form the double salt $\left(\mathrm{NH}_{4}\right)_{2} \mathrm{C}_{2} \mathrm{O}_{4} \mathrm{VO}$ -

1 This Journal, 32, I603 ( $19 \mathrm{ro}$ ).

2 Compt. rend., 104, $106 \mathrm{I}$. 
$\left(\mathrm{C}_{2} \mathrm{O}_{4}\right)$. This salt was recrystallized twice and filtered with suction. It now gave no test for sulfates. Ammonia was next added to a water solution of these crystals, and the brown precipitate was filtered and washed with dilute ammonia. The precipitate was then heated in platinum until no more ammonia was evolved. Part of the residue dissolved in sodium carbonate solution and the rest dissolved after fusion with sodium carbonate. Since the color showed that it had not been entirely reoxidized, a little sodium peroxide was added until the color of the solution disappeared. Both the sodium carbonate and sodium peroxide were of special purity according to the analysis of J. T. Baker.

The material was then treated with carbon dioxide to convert the excess of alkali into bicarbonate. It was next crystallized eight times in porcelain and three times in platinum, with drainage by suction, then four times in platinum with centrifugal drainage. During the final crystallizations it was protected from carbon dioxide by keeping it in a desiccator over potassium hydroxide. The water used in the crystallizations had been distilled from alkalin permanganate, and redistilled after addition of a trace of acid; a block tin or quartz condenser was used.

The sodium vanadate was now neutral, in hot or cold solution, to litmus, methyl orange, phenolphthalein and phenacetolin.

Apparatus and Method. - The thermostat was heated by gas, with a toluene regulator, and the water was kept well stirred. The temperature was usually constant to several hundredths of a degree, except at the higher temperatures, when it occasionally varied as much as $0.2^{\circ}$. The thermometer was standardized by the Bureau of Standards at Washington, and a correction was applied for the emergent stem.

The solution and crystals were rotated in the thermostat in a hard glass tube closed by a well cleaned rubber stopper. When equilibrium had been reached, this tube was supported vertically in the thermostat until the crystals had settled, so that the supernatant liquid could be withdrawn.

A Landolt pipette was used for withdrawal of the solution. It was dried, weighed and kept in a vertical tube in the thermostat until ready for use. A filter of cleaned cotton wool was sometimes used in withdrawing the solutions.

After withdrawing the solution and wiping off the outside of the pipette, it was again weighed. The liquid was then washed out of the pipette and made up to a volume of $500 \mathrm{cc}$.; of this two portions of $100 \mathrm{cc}$. each were taken for analysis.

Analysis of the Solution. - The sodium vanadate was reduced to vanadyl sulfate by the action of sulfur dioxide in the presence of sulfuric acid. The excess of sulfur dioxide was then removed by boiling the 
liquid in an atmosphere of carbon dioxide, and the liquid was titrated while hot, with standard permanganate. The equation is

$$
{ }_{5} \mathrm{~V}_{2} \mathrm{O}_{2}\left(\mathrm{SO}_{4}\right)_{2}+8 \mathrm{H}_{2} \mathrm{SO}_{4}+\underset{5}{2} \mathrm{KMnO}_{2} \mathrm{O}_{2}\left(\mathrm{SO}_{4}\right)_{3}+\mathrm{K}_{2} \mathrm{SO}_{4}+2 \mathrm{MnSO}_{4}+8 \mathrm{H}_{2} \mathrm{O} .
$$

The permanganate solution was standardized approximately against oxalic acid and finally titrated against a known solution of fused sodium vanadate. The sulfur dioxide was prepared by the action of dilute sulfuric acid on sodium sulfite, and the carbon dioxide by the action of hydrochloric acid on marble; the gases were washed before entering the vanadate solution. Duplicate titrations made by this method agreed to within $0.05 \mathrm{cc}$.

Experiments and Results.-A number of preliminary trials were necessary before the proper conditions were secured. It was soon found that a long time was required for solutions of sodium vanadate to reach equilibrium, especially at the lower temperatures.

The following results were obtained with one sample of crystals: The values are expressed in grams of anhydrous vanadate to Ioo grams of water. At $25^{\circ}$, after 24 hours in the thermostat, the solubility obtained was 21.30. After addition of fresh solid and a further run of 30 hours without change of temperature, the solubility was 21.27. After addition of water and a further agitation for 24 hours, the value obtained was 20.73. Saturation had evidently been reached, and the average value Was $2 \mathrm{I}$.IO.

Without addition of water or solid, the temperature was now raised to $40^{\circ}$, and the value obtained was 26.37 ; then more solid was added, and it was agitated for 27 hours more, giving a value of 26.07 . The average value was 26.23 . Another portion was then agitated at $60^{\circ}$ for 24 hours, and gave a value of 32.97 . The temperature was then raised to $75^{\circ}$ and more solid was added. After six hours at this temperature, the value obtained was 38.83 . These results are plotted in curve $A$.

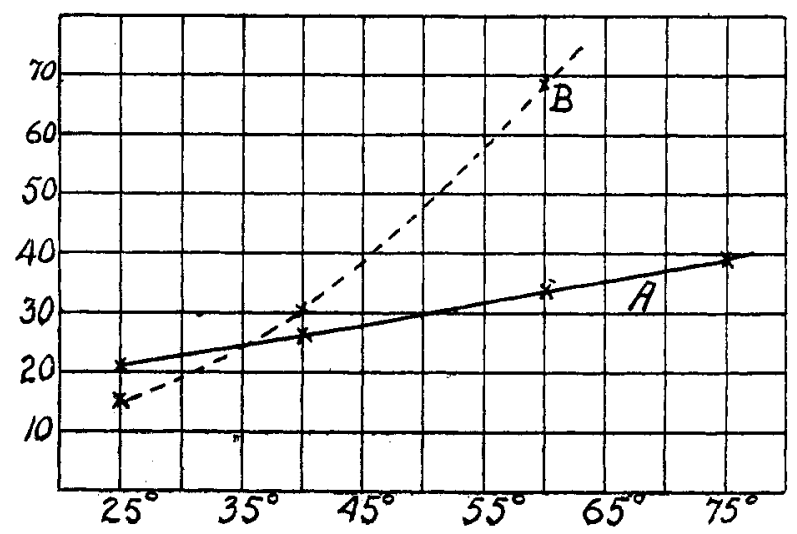


Another sample of sodium vanadate gave quite different values, especially at the higher temperatures. The results are given below in tabular form. Sometimes fresh material was added for a new experiment and sometimes several determinations were made without allowing the thermostat to cool or adding new material. These results are plotted in curve $B$.

$\begin{array}{ccc}\text { Temperature. } & \text { Hours. } & \text { Solubility. } \\ 25^{\circ} & 24 & 15.16 \\ 25 & 31 & 15.31 \\ 40 & 26 & 29.65 \\ 40 & 30 & 30.21 \\ 60 & 10 & 69.93 \\ 60 & 20 & 68.86 \\ 60 & 26 & 67.27 \\ 60 & 26 & 67.38\end{array}$

An attempt was made to get a value at $75^{\circ}$ immediately after one of the experiments at $60^{\circ}$. At first, after raising the temperature to $75^{\circ}$, more solid went into solution, then suddenly more crystals began to form and the mass became nearly solid. It was then diluted with water and rotated again at $75^{\circ}$. The value obtained was 39.22 ; and, after eight hours more without addition of crystals or water, the value was 39.59 . Another trial with the same material gave 38.15. The average was 38.99 , which falls on curve $A$. So the solid phase had evidently changed to the less soluble modification.

The results, therefore, indicate that at least two different solid phases can exist in contact with water solutions, and that their solubility curves cross at about $35^{\circ}$. It is now clear why Maddock could not get consistent results at $25^{\circ}$. Evidently he was sometimes dealing with phase $\mathrm{A}$, and sometimes with phase B, whose solubilities are $2 \mathrm{I}$.ro and 15.23 respectively. At higher temperatures his results agree fairly well with ours.

The next problem was to determin the composition of the two solid phases. This was quite difficult. The crystals were very small, those of phase A were so small that they could not be centrifuged effectively. Both kinds of crystals were anhydrous after exposure to the air, so it was hard to tell just when the mother liquor had been removed.

The first method tried was as follows:

Some of the crystals of phase B were centrifuged, weighed, fused and again weighed. The results were:

$\begin{array}{cc}\text { Wt. of crystals. } & \text { Wt. of anhydrous salt. } \\ 2.4550 & \mathrm{I} .9464 \\ 2.4620 & \mathrm{I} .8372\end{array}$

The loss of weight per hundred parts of anhydrous salt were therefore 26.13 and $34.0 r$, with an average of 30.07 . This corresponds to the formula $\mathrm{NaVO}_{3} \cdot 2 \mathrm{H}_{2} \mathrm{O}$. 
Since it was uncertain whether this loss represents water of crystallization alone, another method was now tried.

A small quantity of sodium chloride solution was added to the solution and crystals of sodium vanadate, and the material was rotated in the thermostat as in an ordinary solubility determination. The crystals were then freed as quickly as possible from the greater part of the solution, and analyses of the moist crystals and of the solution were made. The amount of sodium chloride found in the moist solid was assumed to be a measure of the amount of solution retained. The sodium chloride was determined by precipitating with silver nitrate in nitric acid solution and weighing the silver chloride. In another portion, the water was obtained by careful evaporation and fusion.

The results obtained by this method are given below. In each experiment, the first two horizontal columns give the results of actual analysis. In the third horizontal column, the values for $\mathrm{NaVO}_{3}$ and $\mathrm{H}_{2} \mathrm{O}$ have been calculated from the value for $\mathrm{NaCl}$, so that the proportions are the same as in the first column. In the fourth horizontal column, the values were obtained by subtracting those of the third column from those of the second.

\begin{tabular}{|c|c|c|c|c|c|c|}
\hline Solution, $50^{\circ} \ldots \ldots$ & Phase. & $\begin{array}{l}\mathrm{NaCl} \\
0.1787\end{array}$ & $\begin{array}{l}\mathrm{NaVO}_{3} \\
\mathrm{I} .0538\end{array}$ & $\begin{array}{l}\mathrm{H}_{2} \mathrm{O} \\
3.6505\end{array}$ & $\begin{array}{l}\text { Solubility. } \\
28.3\end{array}$ & $\begin{array}{c}\text { Formula. } \\
\ldots\end{array}$ \\
\hline Moist crystals...... & & 0.0588 & 0.8497 & I. 3 II 4 & $\ldots$ & $\ldots$ \\
\hline Retained solution... & & 0.0588 & 0.3467 & I. $201 \mathrm{I}$ & $\ldots$ & $\ldots$ \\
\hline Dry crystals. $\therefore \ldots \ldots$ & $\mathrm{B}$, & $\cdots$ & 0.5030 & 0.1103 & $\cdots$ & $\mathrm{I} \cdot 49 \mathrm{H}_{2} \mathrm{O}$ \\
\hline Solution, $50^{\circ} \ldots \ldots$ & & 0.2233 & I. 5984 & $4 \cdot 95^{8} 5$ & 32.21 & $\ldots$ \\
\hline Moist crystals...... & & 0.0450 & $3 \cdot 7260$ & 1.7311 & $\ldots$ & $\cdots$ \\
\hline Retained solution... & & $0.045^{\circ}$ & 0.3220 & 0.9992 & $\ldots$ & $\ldots$ \\
\hline Dry crystals....... & $\mathrm{B}$, & $\ldots$ & $3 \cdot 4040$ & 0.7319 & $\ldots$ & I. $46 \mathrm{H}_{2} \mathrm{O}$ \\
\hline Solution, $50^{\circ} \ldots \ldots$ & & 0.1757 & I. 8413 & 5.0185 & 36.7 & $\cdots$ \\
\hline Moist crystals...... & & 0.0034 & 2.3523 & $0.68 \mathrm{r} 7$ & $\cdots$ & $\cdots$ \\
\hline Retained solution... & & 0.0034 & 0.0356 & $0.097 \mathrm{r}$ & $\ldots$ & $\ldots$ \\
\hline Dry crystals....... & $\mathrm{B}$, & $\ldots$ & 2.3167 & 0.5846 & $\ldots$ & $1.72 \mathrm{H}_{2} \mathrm{O}$ \\
\hline Solution, $35^{\circ} \ldots \ldots$ & & 0.1242 & 1.2980 & $7 \cdot 3859$ & 17.6 & $\cdots$ \\
\hline Moist crystals..... & & 0.0489 & I. 9646 & 2.8911 & $\ldots$ & $\cdots$ \\
\hline Retained solution... & & 0.0489 & 0.5110 & 2.9079 & $\cdots$ & $\ldots$ \\
\hline Dry crystals....... & $A$, & $\ldots$ & I. 4536 & -0.0168 & $\ldots$ & $-0.078 \mathrm{H}_{2} \mathrm{O}$ \\
\hline Solution, $50^{\circ}$. & & 0.1683 & I. 1374 & $5.096 \mathrm{r}$ & $22 \cdot 3 I$ & $\cdots$ \\
\hline Moist crystals..... & & $0.057^{2}$ & 2.1868 & 1.7715 & $\ldots$ & $\cdots$ \\
\hline Retained solution... & & 0.0572 & 0.3806 & 1.7320 & $\cdots$ & $\ldots$ \\
\hline Dry crystals........ & A, & $\ldots$ & I. 8062 & 0.0395 & $\cdots$ & o. $148 \mathrm{H}_{2} \mathrm{O}$ \\
\hline
\end{tabular}

The solubility values, as given in the fifth vertical column, are of course lower than for pure sodium vanadate, and vary with the concentration of the sodium chloride. But it is evident from these figures that we had two different phases. To prove that the material used in the first three 
experiments is really phase $B$, we made some solubility determinations at $50^{\circ}$ with the pure substance. The results were $51.64,52.21$ and 52.20 . By a reference to the curve it will be seen that these values are a little too high for curve $B$, but near enough to show that phase $B$ had been obtained.

The values in the last vertical column are probably somewhat too low, since no allowance could be made for the effect of adsorption. In the third experiment the best result for phase $B$ was probably obtained, since the moist crystals were centrifuged quickly before analysis and most of the mother liquor was thus removed. The value $\mathrm{NaVO}_{3} \mathrm{I}^{3} /{ }_{4} \mathrm{H}_{2} \mathrm{O}$ obtained by this method, and the value $\mathrm{NaVO}_{3} 2 \mathrm{H}_{2} \mathrm{O}$ obtained by centrifuging alone, seem to us to show that phase $\mathrm{B}$ is $\mathrm{NaVO}_{3} 2 \mathrm{H}_{2} \mathrm{O}$. From the last two experiments in the table, we conclude that the formula of phase $\mathrm{A}$ is $\mathrm{NaVO}_{3}$.

[Contributions from the Research Laboratory of Physical Chemistry of the Massachusetts INSTITUTE OF TEChNOLOGY. No. 83.]

\section{A SYSTEM OF QUALITATIVE ANALYSIS FOR THE COMMON ELEMENTS.}

PART V.-DETECTION OF THE ACIDIC CONSTITUENTS. ${ }^{1}$

BY ARTHUR A. NOYES,

Received March 26, 1912.

Introduction.

This article forms a continuation of those previously published in This Journal under the same main title. ${ }^{2}$

The purpose of the investigation here described was to work out a more systematic, generally applicable plan for detecting the acidic constituents of substances than those commonly employed. The attempt was also made to develop a series of tests for the various constituents of known and roughly equal sensitiveness. Moreover, the desirability of employing methods by which an approximate estimate of the quantities present could be formed was taken into consideration, as has been done throughout this system of analysis.

The execution of this research has been made possible through the effective aid rendered by Dr. W. C. Bray, Mr. R. D. Gale, and Dr. K. G. Falk, to all of whom I wish to express my great obligation. I am indebted to Dr. W. C. Bray also for invaluable assistance in the preparation of this article for publication.

\section{General Discussion.}

I. The usual method of testing for salts of the very volatil acids consists in liberating them by heating with a stronger acid and testing the

${ }^{1}$ Copyright 1912, by Arthur A. Noyes.

${ }^{2}$ This Journal, 29, I37-205 (1907); 30, 48I-563 (1908); 31, 61 I-637 (1909). 